\title{
A Powder Metallurgy Method for Manufacturing Ti-6Al-4V with Wrought-like Microstructures and Mechanical Properties via Hydrogen Sintering and Phase Transformation (HSPT)
}

\author{
James D. Paramore ${ }^{\mathrm{a}}$, Z. Zak Fang ${ }^{\mathrm{a},}$, , Pei Sun ${ }^{\mathrm{a}}$, Mark Koopman ${ }^{\mathrm{a}}$, K.S. Ravi Chandran ${ }^{\mathrm{a}}$, and Matt Dunstan ${ }^{\mathrm{a}}$ \\ ${ }^{a}$ Department of Metallurgical Engineering \\ University of Utah \\ 135 S 1460 E RM 412 \\ Salt Lake City, UT 84112 \\ USA \\ "Corresponding author: zak.fang@utah.edu,+1(801)581-8128
}

Keywords: titanium alloys; sintering; grain refinement; phase transformation; microstructure

\begin{abstract}
In this paper, the feasibility of producing Ti-6Al-4V with a range of wrought-like microstructures and mechanical properties via a novel powder metallurgy (PM) process with simple heat treatments is investigated. The wrought-like PM Ti-6Al-4V is obtained by sintering blended elemental (BE) powder in a hydrogen atmosphere, followed by conventional Ti-6Al-4V heat treating profiles. This is achieved without resorting to energy-intensive thermomechanical processing (TMP) that is compulsory for producing high performance titanium alloys via wrought processing or traditional powder metallurgy.
\end{abstract}

\section{Manuscript}

Currently, wrought processing is the state of the art for producing Ti alloys with microstructures and mechanical properties necessary for critical applications. However, wrought $\mathrm{Ti}$ is prohibitively expensive for use in most commercial applications, due to the multi-step, energy-intensive, thermomechanical processing (TMP) routes used. Additionally, many Ti components have high buy-to-fly ratios. Because of this, powder metallurgy (PM) has long been sought as a means to reduce the cost of Ti alloys, owing to its near-net-shape (NNS) capabilities [1]. However, low-cost PM Ti typically has relatively poor mechanical properties. Additional $\mathrm{p}$

mechanical properties, such as pre-alloying the powder, pressure-assisted sintering, and thermomechanical work. However, these processes significantly increase cost, thereby offsetting the economic benefits of using PM [2]. Therefore, the key for any successful alternative to wrought processing is to maximize the performance-to-cost ratio of Ti alloys by producing wrought-like microstructures and mechanical properties using low-energy materials and processing routes.

Specifically to PM Ti, the key to achieve mechanical properties that can match that of wrought Ti while maintaining the low cost advantage is to find a way to produce wrought-like microstructures without using pressure-assisted sintering processes or relying on TMP, which is energy-intensive and 
incompatible with the NNS nature of PM. This objective can be achieved only by using low-cost powder, blended elemental alloying, near-net-shape compaction, and pressure-less sintering processes that can deliver the desired microstructures in the as-sintered or heat treated state. Achieving this goal would be a breakthrough that could transform the Ti industry.

Hydrogen sintering and phase transformation (HSPT) is a new, low-cost, blended elemental (BE), press and sinter process for producing titanium alloys from hydrogenated Ti powder. The current authors have previously demonstrated the ability of HSPT to produce Ti-6Al-4V with over $99 \%$ relative density, an ultrafine grain (UFG) microstructure, and extraordinary mechanical properties in the as-sintered state [37]. Using hydrogenated Ti powder has been shown in the literature to have several benefits as a PM Ti feedstock, including improved densification behavior [8]. However, the key innovation of HSPT is the utilization of a dynamically controlled $\mathrm{H}_{2}$ partial pressure during sintering. Hydrogen acts as a temporary alloying element during sintering to refine the microstructure via phase transformations [9]. As such, HSPT has three general steps: $\beta-\mathrm{Ti}(\mathrm{H})$ sintering, phase transformation, and dehydrogenation (Figure 1-a). Densification is activated by the presence of hydrogen during the sintering step. The microstructure is then refined via the phase transformation step. Finally, residual hydrogen is removed by annealing under inert gas or vacuum. A detailed description of the HSPT processing steps has been published previously $[9,10]$ and is also given in the online supplemental information for this paper. For comparison, a typical thermal profile used to produce $\mathrm{Ti}$ alloys from $\mathrm{Ti}$ or $\mathrm{TiH}_{2}$ powder via the traditional method of vacuum sintering is given in Figure 1-b. It should be noted that hydrogen has been previously investigated as a temporary alloying element in thermohydrogen processing (THP) studies [11]. However, HSPT is unique from THP in that it utilizes hydrogen during sintering to simultaneously refine the microstructure.

In the current study, the feasibility of applying simple heat treatments to as-sintered HSPT Ti-6Al-4V in order to generate a range of wrought-like microstructures and mechanical properties is investigated. The heat treatments used in this study were borrowed from wrought processing. Such heat treatments would normally be preceded by thermomechanical work [12]. However, it was hypothesized that the ultrafine microstructure that results from HSPT is a suitable starting point to generate wrought-like microstructures without resorting to energy-intensive thermomechanical work. To further test this hypothesis, identical heat treatments were performed on samples with the coarse lamellar microstructure that results from traditional vacuum sintering.

Figure 1-c and Figure 1-d show schematic thermal profiles that would typically be used in wrought processing of $\alpha+\beta$ Ti alloys to produce a bi-modal (duplex) or fully-equiaxed (globularized) microstructure, respectively [12]. During these heat treatments, the material is first brought to a temperature just below the $\beta$-transus and held for sufficient time to allow formation of globularized or equiaxed primary $\alpha$ and $\beta$ grains. As the material is cooled, the primary $\alpha$ grains that were present at high temperature remain. Relatively fast cooling results in a bi-modal (duplex) microstructure (Supplemental Figure 2-a). During fast cooling, the $\beta$ phase transforms into lamellar colonies of $\alpha$ grains with retained $\beta$ between the $\alpha$ grains; very fast cooling (quenching) results in very fine lamellar or acicular $\alpha$ grains, while a slower cooling rate results in coarser $\alpha$ lamellae. However, if the cooling rate is sufficiently slow, the $\beta$ grains transform into globularized $\alpha$ grains resulting in a so-called fully-equiaxed microstructure. In this structure, essentially all of the $\alpha$ phase is present as equiaxed grains with retained $\beta$ confined to the triple points (Supplemental Figure 2-b).

Detailed descriptions of the powder preparation and compaction methods as well as the furnaces used in this study are available in the online supplemental information. 
Sintering was performed using either HSPT (Figure 1-a) or vacuum sintering (Figure 1-b). The experimental parameters used during HSPT and vacuum sintering in this study are given in detail in the online supplemental information. A final hydrogen content below $10 \mathrm{ppm}$ was consistently achieved using both HSPT and vacuum sintering.

Heat treatments were performed on both HSPT-sintered and vacuum-sintered specimens, using one of the two thermal profiles shown schematically in Figure 1. To study the effect of rapid cooling, the samples were first held at $954^{\circ} \mathrm{C}$ for 1 hour and then quenched in room temperature water (Figure 1-c). To study the effect of slow cooling, the samples were first held at $954^{\circ} \mathrm{C}$ for 1 hour and then furnace cooled $(\sim 10$ ${ }^{\circ} \mathrm{C} / \mathrm{min}$ ) to room temperature (Figure 1-d). All heat treated samples were subjected to an ageing treatment at $550{ }^{\circ} \mathrm{C}$ for 6 hours under $10^{-3} \mathrm{~Pa}\left(10^{-5} \mathrm{mbar}\right)$ vacuum.

Figure 2 shows optical micrographs of Ti-6Al-4V samples that were sintered by HSPT or traditional vacuum sintering with and without subsequent heat treatments. Due to the very fine features in Figure 2-a and $b$, high resolution scanning electron micrographs (SEM) are also given in Supplemental Figure 1. In the optical micrographs, $\alpha$ is the light phase and $\beta$ is the dark phase. However, in the SEM micrographs this relationship is reversed ( $\alpha$ is the dark phase and $\beta$ is the light phase).

Figure 2-a shows the as-sintered Ti-6Al-4V microstructure that results from HSPT (Figure 1-a). As discussed above and shown in previous research $[3-7,9,10]$, this microstructure consists of ultrafine lamellar $\alpha$ grains with discontinuous $\beta$ grains dispersed throughout the matrix.

Figure 2-b shows the microstructure of an HSPT-sintered sample after heat treatment with water quenching (Figure 1-a followed by Figure 1-c). Similar to wrought processing, this heat treatment produced a clearly bi-modal (duplex) microstructure. This microstructure consists of globularized primary grains constituting about $40 \mathrm{vol} \%$ of the microstructure. The remainder of the microstructure consists of ultrafine acicular $\alpha$ grains with dispersed retained $\beta$. It should be noted that some of the primary $\alpha$ grains in the heat treated HSPT samples are still slightly elongated. These results are still preliminary, and it is believed that the morphology of the primary $\alpha$ grains may be further evolved by adjusting the parameters of HSPT and subsequent heat treatments. The size of the globularized primary $\alpha$ grains is on the order of $2 \sim 5 \mu \mathrm{m}$, while the acicular $\alpha$ grains have submicron dimensions.

Figure 2-c shows the microstructure of an HSPT-sintered sample after heat treatment with furnace cooling (Figure 1-a followed by Figure 1-d). This microstructure resembles a fully-equiaxed wrought microstructure produced via hot working and a similar heat treatment and ageing. Again, while the primary $\alpha$ grains are clearly globularized and have a low aspect ratio, some of the grains are still slightly elongated. Therefore, for this result, it may be said that the microstructure is "globularized", as the definition for "equiaxed" does not strictly apply to every $\alpha$ grain. However, as mentioned above, these results are still preliminary and it is believed that adjusting the sintering and heat treating parameters may result in a more equiaxed morphology. After heat treatment, the globularized $\alpha$ grains have an average grain size on the order of $5 \mu \mathrm{m}$.

Figure 2-d shows the microstructure of as-sintered Ti-6Al-4V that results from traditional vacuum sintering (Figure 1-b). As seen in the micrograph, vacuum sintering produces coarse lamellar $\alpha$ grains with a continuous layer of $\beta$ between the lamellae.

Figure 2-e shows the microstructure of a vacuum-sintered sample after heat treatment with water quenching (Figure 1-b followed by Figure 1-c). As would be expected, quenching causes a change in the microstructure, though the results appear to be undesirable with regards to mechanical properties. The resulting microstructure contains large elongated $\alpha$ grains with a high aspect ratio. The remainder of the 
microstructure consists of very fine acicular $\alpha$ grains with retained $\beta$ that form during quenching. While this microstructure is bi-modal, it does not resemble a bi-modal structure with fine globularized primary $\alpha$ grains that is sought in wrought processing. Additionally, the elongated $\alpha$ grains, which have an HCP crystal structure, have few slip systems and would likely result in long brittle crack paths.

Figure 2-f shows the microstructure of a vacuum-sintered sample after heat treatment with slow cooling (Figure 1-b followed by Figure 1-d). As shown, the microstructure is essentially unchanged from the assintered specimen. Therefore, it can be deduced that this heat treatment is ineffective for a vacuumsintered sample.

The mechanisms by which the microstructure evolves during heat treatments of HSPT Ti-6Al-4V are not yet conclusively known. However, it is hypothesized that the high surface energy of the UFG microstructure provides sufficient driving force to form globularized $\alpha$ and $\beta$ grains at the treatment temperature. When the material is quenched, the globularized $\alpha$ grains remain and the $\beta$ grains transform into acicular grains. The aspect ratio of the grains that form during cooling is a function of the diffusion path length of the alloying elements during partitioning (i.e. cooling rate). Therefore, when the material is cooled slowly, the $\beta$ grains transform into $\alpha$ grains with a relatively low aspect ratio. Additionally, it is known that $\mathrm{TiH}_{2}$ forms during the cooling segments of the sintering profile [9]. Therefore, it is possible that the formation of the less dense $\mathrm{TiH}_{2}$ phase would provide sufficient strain in the surrounding matrix to drive recrystallization during subsequent heat treatments.

It is believed that the microstructure resulting from vacuum sintering is too coarse and not conducive to forming the globularized $\alpha+\beta$ microstructure that serves as a necessary intermediate at the treatment temperature. Therefore, it is proposed that vacuum-sintered samples are not capable of forming globularized grains via simple heat treatments without first inducing a driving force for the necessary reactions via thermomechanical work.

To determine the correlation between structure and properties of HSPT Ti-6Al-4V, quasi-static tensile tests were performed on HSPT samples with the as-sintered, bi-modal, and "globularized" microstructures shown in Figure 2-a through c. Representative engineering stress-strain curves for each of these conditions is given in Figure 3. Additionally, the range of tensile properties for each of these conditions are given in Table 1 along with literature values for wrought Ti-6Al-4V after various heat treatments [13] as well as the ASTM standard for grade 5 Ti-6Al-4V [14]. As shown, the heat treatments have a distinct effect on mechanical properties. The "globularized" condition shows the greatest ductility, while the bimodal condition has the highest strength.

The microstructure shown in Figure 2, along with the tensile data given in Table 1, demonstrate a clear correlation between processing, structure, and properties of Ti-6Al-4V produced via HSPT. It should be noted that while the different microstructures produced a wide range of mechanical properties, all the samples have both strength and ductility well beyond ASTM standards for wrought Ti-6Al-4V. Additionally, each of these conditions is either comparable or superior to typical literature values corresponding to similar wrought processing heat treatments. Therefore, these data indicate that HSPT has the ability to produce a wide range of wrought-like microstructures. As such, this process would be suitable for producing Ti alloys with application-tailored mechanical properties.

It should be pointed out that, even though HSPT Ti alloys have a very high sintered density, there will always be residual porosities in the as-sintered state. Porosity has important implications for the mechanical properties of PM alloys, especially fatigue performance. Therefore, methods to remove the residual porosity are currently being investigated. One of these approaches is to subject the as-sintered samples to gaseous isostatic forging (GIF). GIF is a rapid, low-cost, NNS-compatible process that uses 
rapid heating and isostatic pneumatic pressure to close residual porosity [15]. Preliminary data indicates that GIF is indeed capable of removing the residual porosity of HSPT-sintered Ti-6Al-4V and producing fatigue properties on par with high performance wrought Ti-6Al-4V. Therefore, combining HSPT with simple heat treatments and GIF can produce porosity-free titanium alloys with wrought-like microstructures and properties.

In conclusion, the results of this work demonstrate that wrought-like microstructures and mechanical properties can indeed be produced using the PM method described herein. The wrought-like PM Ti is obtained by sintering blended elemental powder in a hydrogen atmosphere, followed by conventional Ti$6 \mathrm{Al}-4 \mathrm{~V}$ heat treating profiles. It was found that the ability to produce wrought-like PM Ti-6Al-4V is unique to HSPT, as vacuum sintering did not produce the same results after heat treatment. As such, these results indicate the potential for HSPT to be the first truly viable low-cost alternative to wrought processing for producing high performance Ti alloys.

\section{Acknowledgements}

The authors acknowledge funding support by the US Department of Energy, Innovative Manufacturing Initiative (DEEE0005761), through the Advanced Manufacturing Office and the Office of Energy Efficiency and Renewable Energy. Raw materials were provided by Reading Alloys (AMETEK).

\section{Figure/Table Captions}

Figure 1: Thermal profiles used for: a) HSPT sintering and dehydrogenation, b) vacuum sintering, c) heat treating with rapid cooling (water quenching), and d) heat treating with furnace cooling.

Figure 2: Optical micrographs of Ti-6Al-4V: a) as-sintered HSPT, b) HSPT after heat treatment with water quench, c) HSPT after heat treatment with furnace cooling, d) as-vacuum-sintered, e) vacuumsintered after heat treatment with water quench, and f) vacuum-sintered after heat treatment with furnace cooling.

Figure 3: Representative engineering stress-strain curves of HSPT Ti-6Al-4V with the as-sintered, "globularized", and bi-modal microstructures shown in Figure 2-a, b, and c, respectively.

Table 1: Range of tensile properties for Ti-6Al-4V produced via HSPT, typical values from literature for wrought Ti-6Al-4V after various heat treatments [13], and the ASTM standard for annealed grade 5 Ti6Al-4V [14]. Note: the HSPT tensile data shown here is from sub-size ASTM E8 tensile bars with a 6.35 $\mathrm{mm}(0.25$ ") diameter by $25.4 \mathrm{~mm}$ (1") long gauge.

\section{References}

[1] D. Eylon, F.H. (Sam) Froes, S. Abkowitz, in:, ASM Handbook, Vol. 7 Powder Met. Technol. Appl., ASM, 1998, pp. 874-886.

[2] Z.Z. Fang, P. Sun, Key Eng. Mater. 520 (2012) 15. 
[3] H. Wang, M. Lefler, Z.Z. Fang, T. Lei, S. Fang, J. Zhang, Q. Zhao, Key Eng. Mater. 436 (2010) 157.

[4] H. Wang, Z.Z. Fang, P. Sun, Int. J. Powder Metall. 46 (2010) 45.

[5] Z.Z. Fang, P. Sun, H. Wang, Adv. Eng. Mater. 14 (2012) 383.

[6] P. Sun, Z.Z. Fang, M. Koopman, Adv. Eng. Mater. 15 (2013) 1007.

[7] Z.Z. Fang, P. Sun, J. Paramore, H. Wang, M. Koopman, L. Yang, Powder Metallurgy Methods for the Production of Fine and Ultrafine Grain Ti and Ti Alloys, US 2014/0255240 A1, 2014.

[8] O.M. Ivasishin, D.G. Savvakin, F. Froes, V.C. Mokson, K.A. Bondareva, Powder Metall. Met. Ceram. 41 (2002) 382.

[9] P. Sun, Z.Z. Fang, M. Koopman, J. Paramore, K.S.R. Chandran, R. Yang, J. Lu, Acta Mater. 84 (2015) 29.

[10] J.D. Paramore, Z.Z. Fang, P. Sun, in:, M. Qian, F.H. (Sam) Froes (Eds.), Titan. Powder Metall., 1st ed., Butterworth-Heinemann, Oxford, 2015, pp. 163-182.

[11] F.H. Froes, O.N. Senkov, J.I. Qazi, Int. Mater. Rev. 49 (2004) 227.

[12] G. Lütjering, J.C. Williams, Titanium, 2nd ed., Springer, Berlin Heidelberg New York, 2003.

[13] R. Boyer, G. Welsch, E.W. Collings, Materials Properties Handbook - Titanium Alloys, ASM International, 1994.

[14] ASTM Standard B348-10, Standard Specification for Titanium and Titanium Alloy Bars and Billets, ASTM, West Conshohocken, PA, 2010.

[15] E.S. Hodge, R.F. Tavenner, Method for Pneumatic Isostatic Processing of a Workpiece, US $5816090,1998$. 


\begin{tabular}{lccc}
\hline Condition & $\begin{array}{c}\text { UTS } \\
\text { MPa }\end{array}$ & $\begin{array}{c}\boldsymbol{\sigma}_{\mathbf{y}, 0.2 \%} \\
\text { MPa }\end{array}$ & $\begin{array}{c}\text { Elongation } \\
\mathbf{\%}\end{array}$ \\
\hline HSPT & & & \\
$\quad$ As-sintered HSPT (Figure 2-a) & $994-1024$ & $930-974$ & $13.8-17.8$ \\
Bi-modal (Figure 2-b) & $1070-1076$ & $981-981$ & $10.7-11.9$ \\
$\quad$ "Globularized" (Figure 2-c) & $949-952$ & $872-881$ & $17.6-19.2$ \\
$\quad \begin{array}{l}\text { Wrought } \\
\alpha+\beta \text { forged + recrystallization annealed [12] }\end{array}$ & 876 & 711 & 12.4 \\
$\quad \alpha+\beta$ forged + solution treatment and age [12] & 938 & 876 & 15.2 \\
$\alpha+\beta$ forged + duplex annealing [12] & 911 & 856 & 15.3 \\
ASTM Standard & & & \\
$\quad$ B348 (Grade 5 Ti-6Al-4V) [13] & 895 & 828 & 10.0 \\
\hline
\end{tabular}


Click here to download high resolution image

\section{Sintering Profiles}
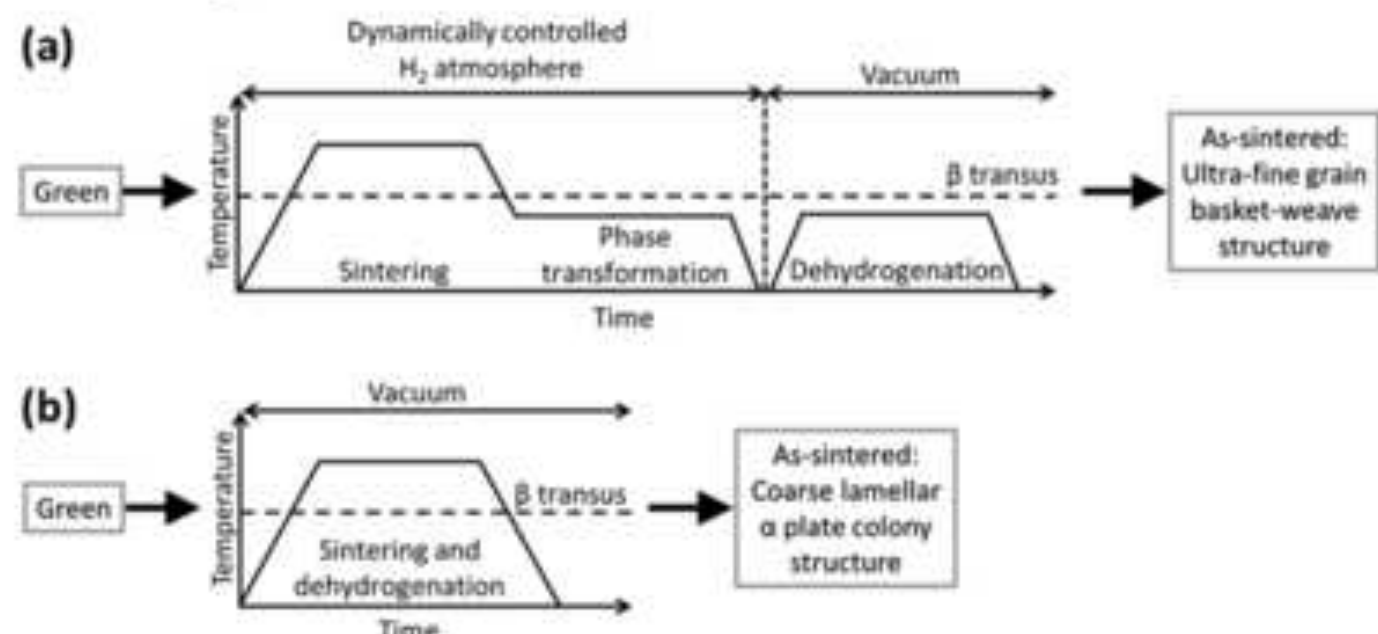

\section{Heat Treating Profiles}

(c)

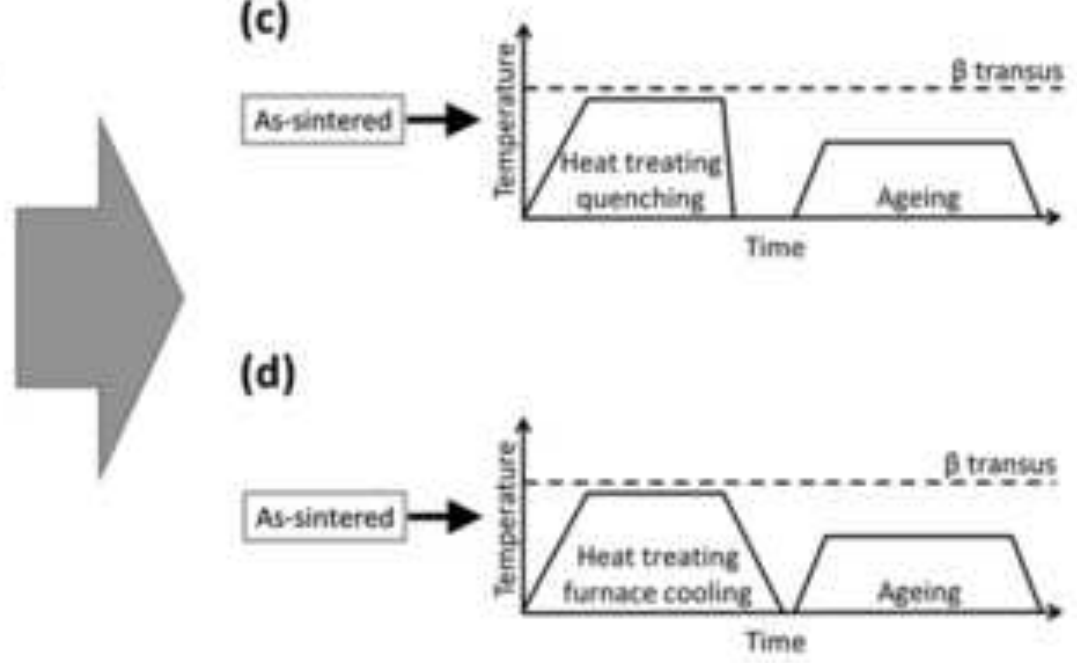




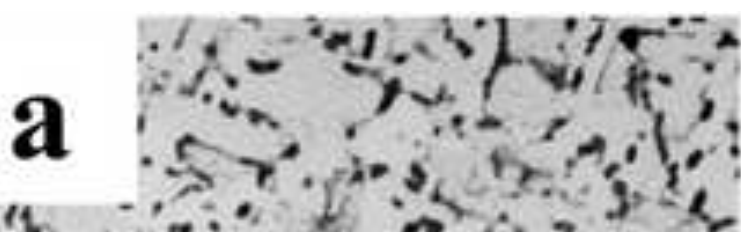

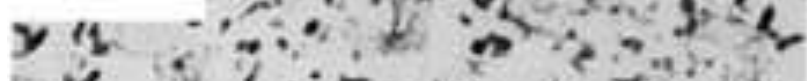

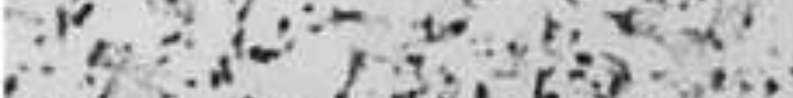

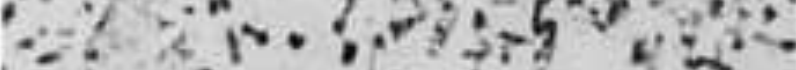

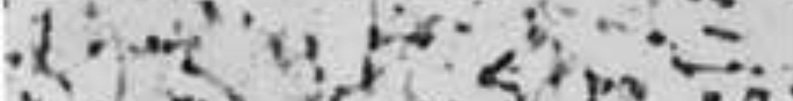

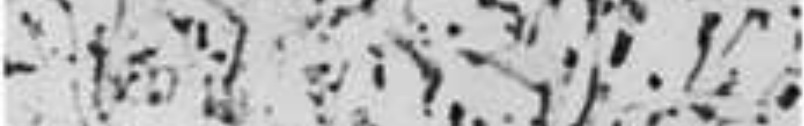

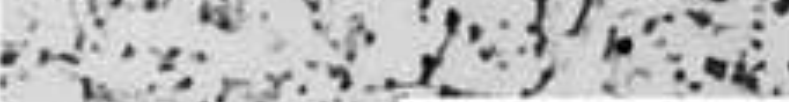

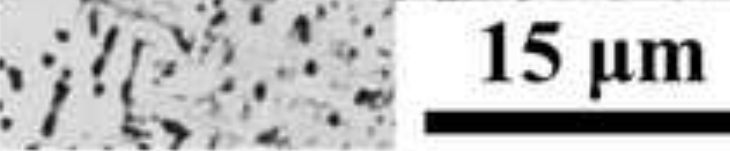

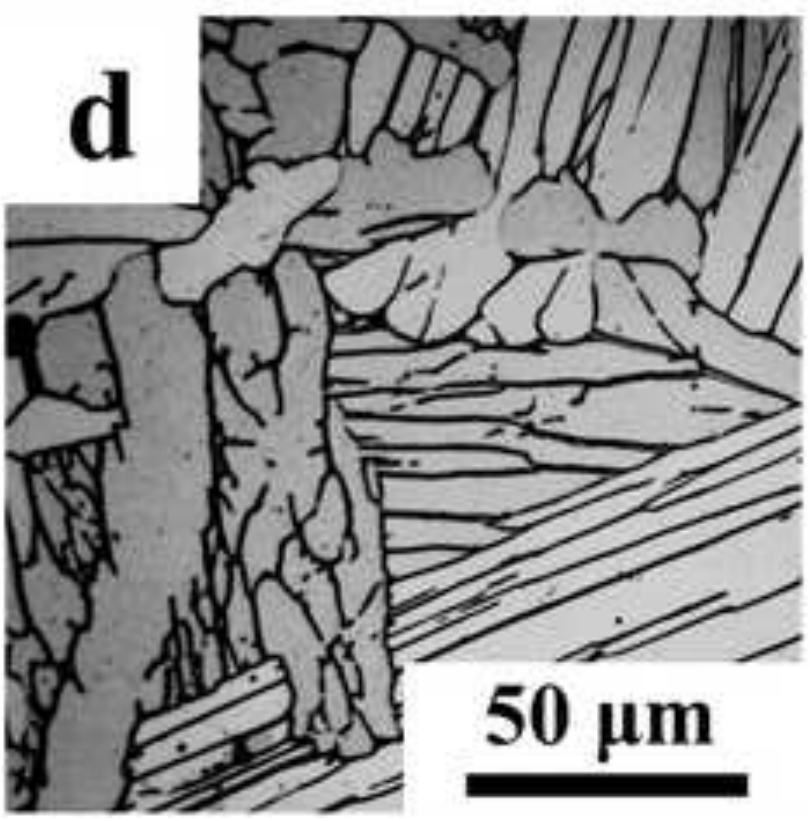

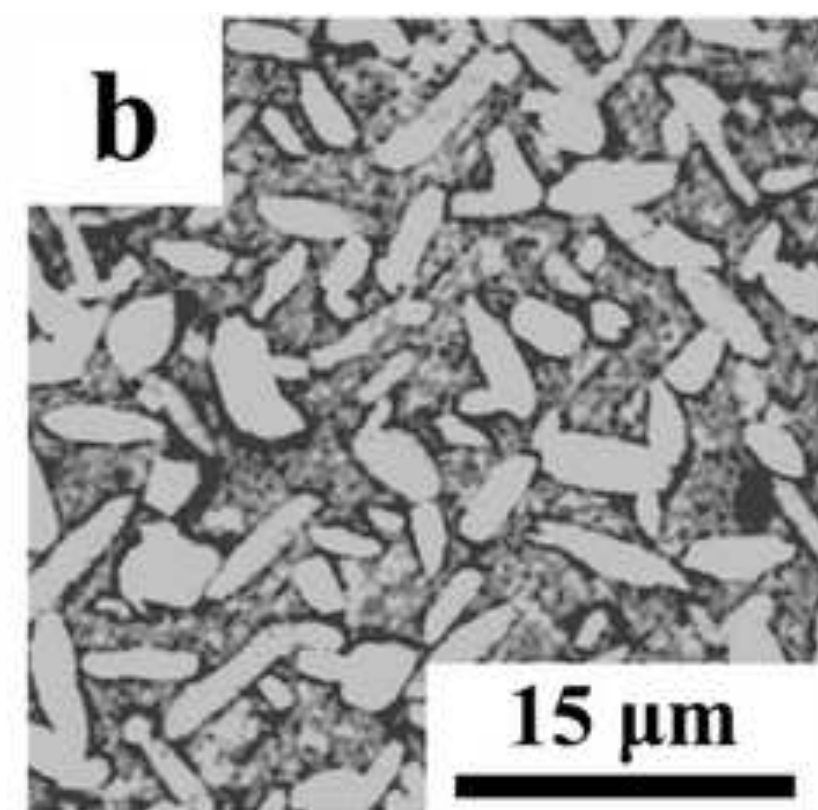
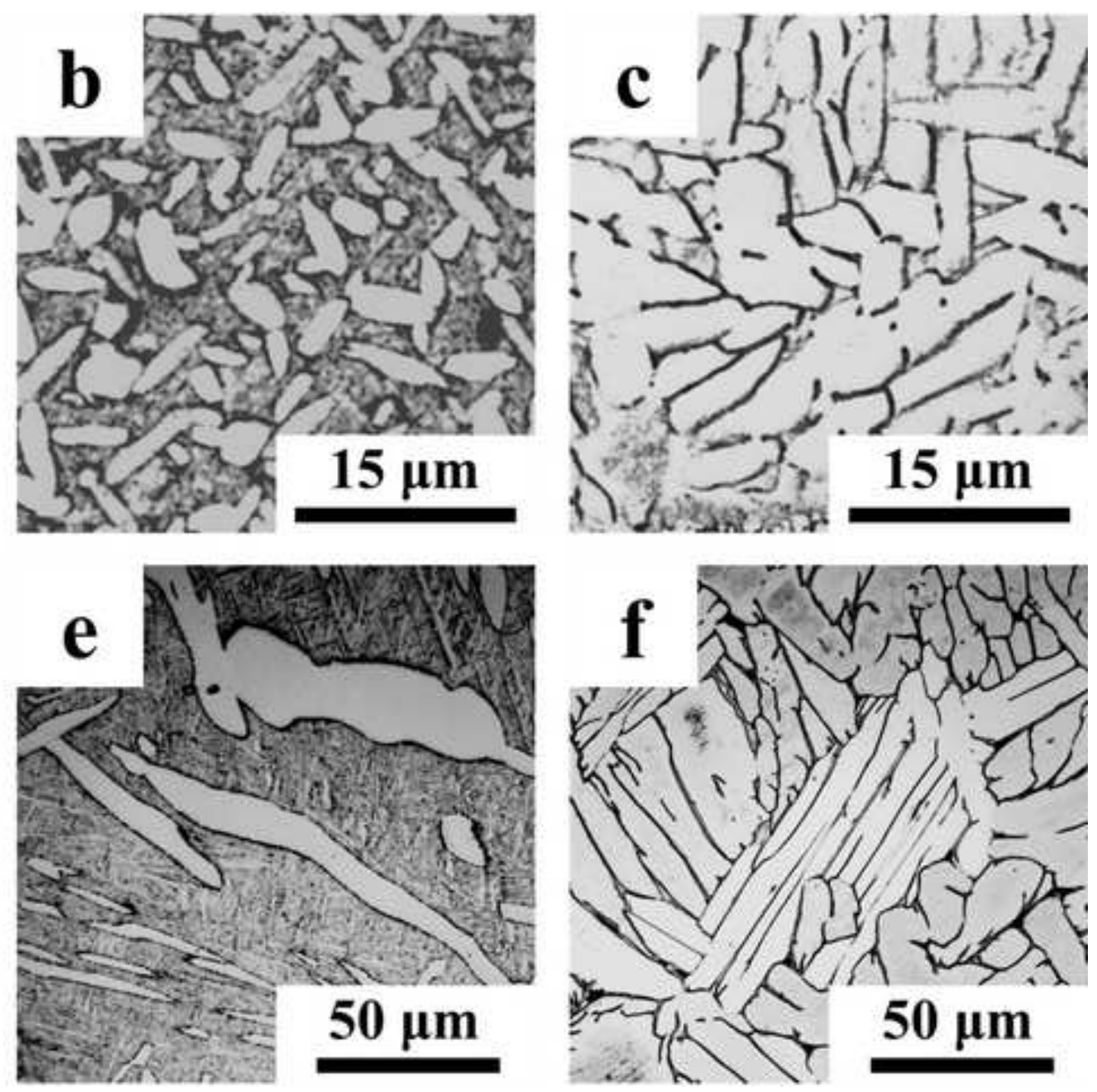


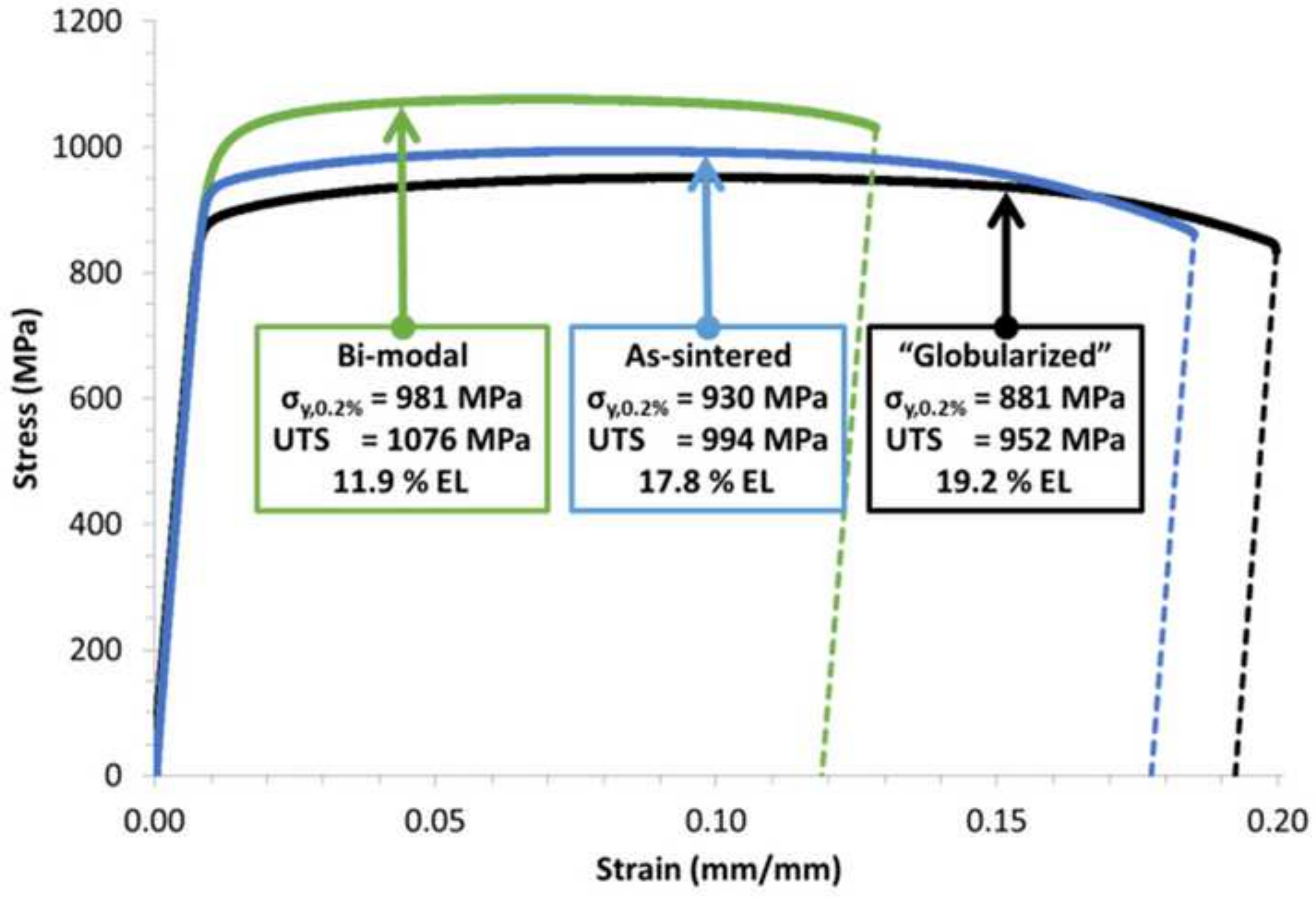




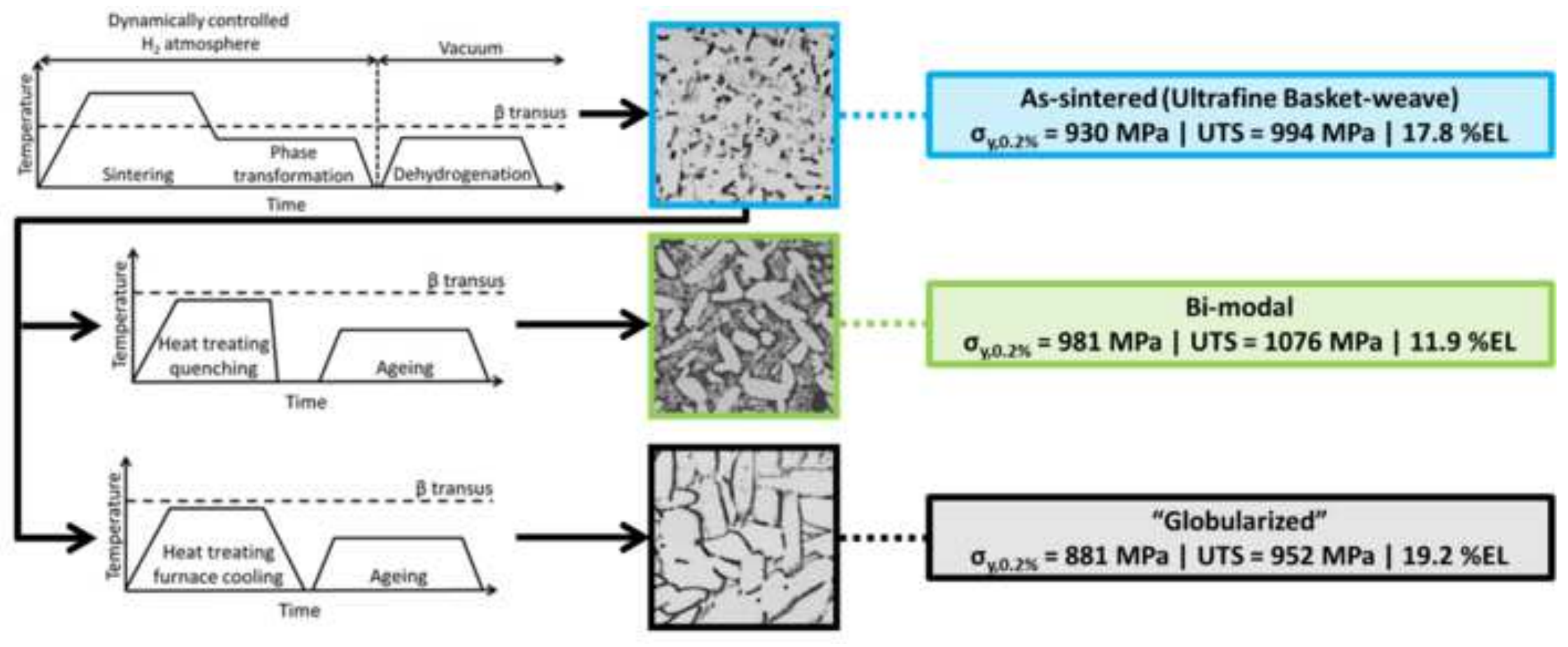

